\title{
EVALUASI SISTEM PREMI PANEN TERHADAP KINERJA KARYAWAN PANEN PADA PERKEBUNAN KELAPA SAWIT (Elaeis guineensis Jacq.) DI PT. SENTOSA KALIMANTAN JAYA
}

\section{EVALUATION OF HARVEST PREMIUM SYSTEMS ON HARVEST EMPLOYEE PERFORMANCE IN OIL PALM PLANTATION (Elaeis guineensis Jacq.) IN PT. SENTOSA KALIMANTAN JAYA}

\author{
Barmas Indah Sari¹, Rusli Anwar ${ }^{1}$, Rusmini ${ }^{1}$ \\ ${ }^{1}$ Politeknik Pertanian Negeri Samarinda, Kampus Gunung Panjang, Jl. Samratulangi, \\ Samarinda, Indonesia \\ barmasindahsari21@gmail.com
}

\begin{abstract}
This research is motivated by the company imposing a premium system on harvest employees with the aim of encouraging harvest employees to work even harder, so as to provide results in increasing the quality and quantity of harvest which will result in profits for the company. Therefore the aim of this research is to be able to evaluate the harvest premium system on the performance of oil palm harvest employees and to identify the characteristics of harvest employees in the Afdeling scope of an oil palm plantation company.

The research method used is to take primary data in the form of observations and observations, field data, documentation, questionnaires and secondary data in the form of documents from the company with the sample method is the Slovin formula which is done randomly with the number of respondents 26 harvest employees then process the data using rock microsoft office. The data analysis method used is a simple descriptive statistical method using the data and information obtained and the Likert scale.

The results of this study indicate that the harvest premium system implemented by PT. Sentosa Kalimantan Jaya (SKJ) is already good and has become a motivation for harvesters to work productively with results that can exceed the base or harvest target set by the company. On average, the harvester was able to harvest 255 jugs / person while the base was 135 for Afdeling 4 and the average harvester was able to harvest 245 jubils / person while the base was 135 for Afdeling 5, the difference was thought to be due to differences in the abilities of each worker., differences in land conditions and crops harvested. Characteristics of respondents related to the performance parameters of harvest employees, from the age factor that is dominated is the productive age of 20-40 years in terms of working, the sex of harvest employees as a whole is male as many as 26 respondents, the majority of harvest employees are educated at elementary school (elementary school) Most of the existing employees also have sufficient 2-4 years of experience, this is a sufficiently supportive factor for the success of harvest employees. Harvest employee performance of PT. Sentosa Kalimantan Jaya (SKJ) has performed very well (4.76) due to quantity, quality, timeliness and attendance.
\end{abstract}

Keywords: premium harvest, evaluation, employee performance.

\section{PENDAHULUAN}

Indonesia merupakan Negara penghasil kelapa sawit terbesar di dunia. Kebutuhan buah kelapa sawit meningkat tajam seiring dengan meningkatnya kebutuhan crude palm oil (CPO) dunia. Oleh karenanya, peluang perkebunan kelapa sawit dan industri pengolahan kelapa sawit (PKS) masih sangat prospek, baik untuk memenuhi pasar dalam dan luar negeri (Pardamean, 2011).

Tanaman kelapa sawit adalah tanaman penghasil minyak nabati yang dapat menjadi andalan dimasa depan karena berbagai kegunaannya bagi kebutuhan manusia. Kelapa sawit memiliki arti penting bagi pembangunan nasional Indonesia. Selain menciptakan kesempatan kerja yang mengarah pada kesejahteraan masyarakat, juga sebagai 
sumber devisa negara (Purwanto, 2016). Menurut Mangkunegara (2009) yang menyatakan bahwa kinerja memiliki hubungan erat dengan motivasi. Motivasi merupakan kondisi atau energi untuk menggerakkan diri karyawan yang terarah atau tertuju untuk mencapai tujuan organisasi perusahaan. Sikap mental karyawan yang positif terhadap situasi kerja itulah yang memperkuat motivasi kerjanya untuk untuk mencapai kinerja yang maksimal.Menurut Sari (2008) yang menyatakan bahwa motivasi inilah yang menjadi yang sangat mempengaruhi karakteristik individu dari masing-masing individu itu sendiri. Oleh karena itu perbedaan karakteristik individu dari setiap karyawan, jika suatu perusahaan ingin mencapai tujuan organisasi maka karakteristik harus diperhatikan. Dari perbedaan-perbedaan karakteristik individu dapat menjelaskan kinerja karyawan yang satu berbeda dengan karyawan yang lainnya. Menurut llyas (2002) yang menyatakan bahwa Keberhasilan dan peningkatan hasil kerja seorang karyawan dapat dipengaruhi oleh faktor karakteristik individu yang terdir atas usia, jenis kelamin, tingkat pendidikan dan pengalaman kerja.Motivasi muncul dari diri manusia karena adanya dorongan untuk suatu tujuan yang menyangkut kebutuhan. Motivasi sebagai suatu hal pokok yang menjadi dorongan setiap motif untuk bekerja (Ariep dkk., 2003). Adanya promosi, gaji, upah, serta tunjangan yang diberikan perusahaan merupakan alat untuk meningkatkan kinerja dan prestasi karyawannya. Dengan adanya pemberiaan tambahan pendapatan diluar gaji pokok seperti tunjangan, lembur, dan insentif adalah salah satu alat yang bisa perusahaan lakukan untuk memotivasi karyawan dalam memberikan prestasi yang dimiliki kepada perusahaan.

Menurut Wungu (2003) premi merupakan bayaran lebih yang diberikan perusahaan karena pegawai harus bekerja lebih keras untuk berbagai keadaan atau kondisi kerja yang kurang nyaman. Pegawai mendapat premi karena pegawai tersebut bekerja melebihi waktu kerja normal atau lembur, kerja saat hari libur, atau karena prestasi kerja dan produktivitas pegawai dalam bekerja. Selain itu menurut Ghani (2003), premi adalah pendapatan yang diperoleh pekerja apabila telah melampaui batas ketentuan yang telah ditetapkan pengusaha/perusahaan. Penelitian yang dilakukan ini terbatas pada suatu lingkup Afdeling yang memiliki luasan berkisar antara 500 - 700 ha. Oleh karena itu, penelitian ini meliputi 2 Afdeling yaitu Afdeling 4 dan Afdeling 5 setiap Afdeling memiliki karyawan sebanyak 18 karyawan panen. Objek dalam penelitian ini adalah kegiatan panen, data yang dibutuhkan meliputi data luasan tanaman serta kondisi lahan, umur tanaman, target produksi, jumlah karyawan serta sistem pengupahan yang diterapkan oleh perusahaan.

Tujuan penelitian ini adalah untuk dapat mengevaluasi sistem premi panen terhadap kinerja karyawan panen kelapa sawit dan mengidentifikasi karakteristik karyawan panen pada lingkup Afdeling disebuah perusahaan perkebunan kelapa sawit. Hasil penelitian ini diharapkan dapat menambah wawasan dan memberikan manfaat kepada pihak yang membutuhkan sebagai acuan terhadap penerapan sistem premi panen terhadap kinerja karyawan panen perkebunan kelapa sawit.

\section{METODOLOGI}

Untuk tujuan mendeskripsikan sistem premi panen dan premi panen di lokasi penelitian jenis data yang diperlukan adalah data primer yang berupa pengamatan serta data lapangan, dokumentasi dan data sekunder yaitu berupa dokumen perusahaan serta studi pustaka. Teknik pengambilan datanya dengan cara melakukan observasi dan data kebijakan perusahaan kemudian data tersebut dianalisa dengan cara deskriptif dan perbandingan dengan standar umum perusahaan perkebunan. Hasil yang diharapkan adalah mengetahui sistem panen dan premi panen yang diterapkan oleh perusahaan yang diteliti.

Untuk mendeskripsikan karakteristik karyawan yang berkaitan 
dengan usia, jenis kelamin, tingkat pendidikan dan pengalaman kerja maka data yang diperlukan adalah data primer yaitu berupa pengamatan, data lapangan dan data sekunder yaitu berupa dokumen perusahaan serta studi pustaka. Teknik pengambilan datanya dengan cara melakukan observasi, kemudian data tersebut dianalisa dengan cara deskriptif. Hasil yang diharapkan mengetahui karakteristik karyawan panen yang ada di perusahaan.

Untuk mendeskripsikan kinerja karyawan yang berkaitan dengan kuantitas hasil, kualitas hasil, ketepatan waktu, dan kehadiran maka jenis data yang diperlukan adalah data primer yaitu berupa pengamatan serta data lapangan dan dokumentasi. Teknik pengambilan datanya dengan cara melakukan observasi dan kuesioner, kemudian data tersebut dianalisa dengan cara scoring hasil skala likert. Hasil yang diharapkan adalah mengetahui tingkat kinerja karyawan. Untuk mendeskripsikan faktor penunjang kerja karyawan panen seperti alat kerja, transportasi kegiatan, upah dan fasilitas yang diterima maka jenis data yang diperlukan adalah data primer yaitu berupa pengamatan dan data lapangan, dokumentasi dan data sekunder yaitu dokumen perusahaan dan studi pustaka. Teknik pengambilan datanya dengan cara melakukan observasi, kemudian data tersebut dianalisa dengan cara deskriptif dan perbandingan dengan standar yang telah diterapkan di perusahaan.

\section{HASIL DAN PEMBAHASAN}

\section{Premi Panen \\ Premi panen merupakan} tambahan upah atau gaji untuk pemanen. Premi diberikan dengan tujuan meningkatkan prestasi panen, baik dalam kuantitas maupun kualitasnya. Premi panen diberikan kepada pemanen apabila jumlah janjang yang dipanen melebihi basis panen berdasarkan tahun tanam. Basis panen dan tahun tanam pada kedua Afdeling sama yaitu basis panen 135 janjang dan tahun tanam 2010. Basis dan premi panen dapat dilihat pada Lampiran 1.

Secara rinci tentang data premi panen pada tanggal 19-24 September 2019 di lokasi Afdeling 4 yang menjadi objek penelitian dapat dilihat pada tabel 4.

Tabel 4. Rekapitulasi Premi Panen Afdeling 4

\begin{tabular}{|c|c|c|c|c|}
\hline \multicolumn{5}{|c|}{ Afdeling 4} \\
\hline No & Nama & Gaji Pokok (Rp) & Nilai Premi (Rp) & $\begin{array}{c}\text { Prestasi } \\
\text { (Janjang) }\end{array}$ \\
\hline 1. & Dinar & 124.840 & 56.176 & 258 \\
\hline 2. & Baharuddin & 124.840 & 62.353 & 272 \\
\hline 3. & Armindo Flora D & 124.840 & 49.325 & 243 \\
\hline 4. & Moh. Iksan & 124.840 & 47.086 & 238 \\
\hline 5. & Gerson Adu & 124.840 & 29.300 & 199 \\
\hline 6. & Laurensius Saju & 124.840 & 92.718 & 339 \\
\hline 7. & Risal & 124.840 & 37.905 & 218 \\
\hline 8. & Amirudin & 124.840 & 56.176 & 258 \\
\hline 9. & Antonius Siga Koa & 124.840 & 62.619 & 273 \\
\hline 10. & Marselinus Tena & 124.840 & 31.712 & 205 \\
\hline 11. & Primus Meze & 124.840 & 81.052 & 313 \\
\hline 12. & Wondelinus Moat W & 124.840 & 43.725 & 231 \\
\hline 13. & Arnoldus Bura & 124.840 & 60.240 & 267 \\
\hline & Jumlah & 1.622 .920 & 710.387 & 3.314 \\
\hline & Rata-rata & 124.840 & 54.645 & 255 \\
\hline
\end{tabular}


Berdasarkan data yang disajikan tabel 4 dapat dijelaskan bahwa premi panen yang ada di lokasi penelitian pada Afdeling 4 memiliki hasil rata-rata gaji pokok perorangan Rp. 124.840 sedangkan rata-rata premi perorangan
Rp. 54.645 dan rata-rata prestasi (janjang) perorangan 255 janjang.Secara rinci tentang data premi panen pada tanggal 19-24 September 2019 di lokasi Afdeling 5 yang menjadi objek penelitian dapat dilihat pada tabel 5.

Tabel 5. Rekapitulasi Premi Panen Afdeling 5

\begin{tabular}{|c|c|c|c|c|}
\hline \multicolumn{5}{|c|}{ Afdeling 5} \\
\hline No & Nama & Gaji Pokok (Rp) & Nilai Premi $(R p)$ & Prestasi (Janjang) \\
\hline 1. & Modetus & 124.840 & 89.637 & 332 \\
\hline 2. & Salman & 124.840 & 35.195 & 212 \\
\hline 3. & Buddin & 124.840 & 25.825 & 192 \\
\hline 4. & Upra & 124.840 & 28.086 & 197 \\
\hline 5. & Avelinus Arsoni & 124.840 & 42.858 & 229 \\
\hline 6. & Asmal & 124.840 & 63.566 & 275 \\
\hline 7. & Harison & 124.840 & 72.195 & 294 \\
\hline 8. & Derson & 124.840 & 87.791 & 328 \\
\hline 9. & Idris Paweloi & 124.840 & 40.518 & 225 \\
\hline 10. & Yasintus Dias & 124.840 & 42.818 & 229 \\
\hline 11. & Muh. Ramli & 124.840 & 55.011 & 255 \\
\hline 12. & Risky & 124.840 & 32.331 & 206 \\
\hline 13. & Asnul & 124.840 & 32.009 & 205 \\
\hline & Jumlah & 1.622 .920 & 647.840 & 3.179 \\
\hline & Rata-rata & 124.840 & 49.834 & 245 \\
\hline
\end{tabular}

Berdasarkan data yang disajikan tabel 5 dapat dijelaskan bahwa premi panen yang ada di lokasi penelitian pada Afdeling 5 memiliki hasil rata-rata gaji pokok perorangan sebesar Rp. 124.840 sedangkan rata-rata premi perorangan Rp. 49.834 dan rata-rata prestasi (janjang) perorangan 245 janjang.

Karakteristik Responden

Dalam penelitian ini karakteristik responden merupakan aspek yang juga digali secara mendalam, karena karakteristik responden sangat menentukan kemampuan kerja karyawan dalam tugasnya sebagai pemanen. Karakteristik responden dikelompokkan dalam kategori berdasarkan usia, jenis kelamin, tingkat pendidikan dan pengalaman kerja. Secara rinci karakteristik responden dapat dijelaskan sebagai berikut:

a. Usia

Usia responden sangat penting untuk diketahui karena berkaitan dengan usia yang produktif atau tidaknya. Data karakteristik responden dalam penelitian berdasarkan usia dapat dilihat pada tabel 6.

Tabel 6. Distribusi jawaban responden berdasarkan usia

\begin{tabular}{cccc}
\hline No & Usia (Tahun) & Frekuensi & Persentase $(\%)$ \\
\hline 1. & $20-30$ & 10 & $39 \%$ \\
2. & $31-40$ & 8 & $31 \%$ \\
3. & $41-50$ & 5 & $19 \%$ \\
4. & $>50$ & 3 & $11 \%$ \\
\hline & Jumlah & 26 & $100 \%$ \\
\hline
\end{tabular}


Berdasarkan data pada tabel 6 dapat dijelaskan bahwa usia responden terbanyak ialah dalam kisaran usia 20-30

sebanyak 10 responden dengan persentase $39 \%$, diikuti dengan rentang usia $\quad 31-40$ sebanyak 8 responden dengan persentase $31 \%$, diikuti dengan rentang usia 41-50 sebanyak 5 responden dengan persentase $19 \%$ dan rentang usia $\geq 50$ sebanyak 3 responden dengan persentase $11 \%$.

b. Jenis Kelamin

Jenis kelamin responden sangat penting untuk diketahui karena sangat terkait dengan kesesuaian antara pekerjaan yang ditanganinya dengan jenis kelamin responden tersebut. Data karakteristik responden dalam penelitian ini berdasarkan jenis kelamin dapat dilihat pada tabel 7 .

Tabel 7. Distribusi jawaban responden berdasarkan jenis kelamin

\begin{tabular}{cccc}
\hline No & Jenis Kelamin & Frekuensi & Persentase (\%) \\
\hline 1. & Laki-laki & 26 & $100 \%$ \\
2. & Perempuan & 0 & $0 \%$ \\
\hline & Jumlah & 26 & $100 \%$ \\
\hline
\end{tabular}

Berdasarkan data pada tabel 7 dapat dijelaskan bahwa responden yaitu 26 responden yang diteliti keseluruhannya adalah berjenis kelamin laki-laki atau $100 \%$ sedangkan pekerja perempuan tidak ada atau $0 \%$. c. Tingkat Pendidikan

Tingkat pendidikan responden yaitu SD, SLTP dan SLTA. Data karakteristik responden berdasarkan tingkat pendidikan terakhir dapat dilihat pada tabel 8.

Tabel 8. Distribusi jawaban responden berdasarkan tingkat pendidikan

\begin{tabular}{cccc}
\hline No & Pendidikan & Frekuensi & Persentase $(\%)$ \\
\hline 1. & SD & 21 & $81 \%$ \\
2. & SLTP & 3 & $11 \%$ \\
3. & SLTA & 2 & $8 \%$ \\
\hline & Jumlah & 26 & $100 \%$ \\
\hline
\end{tabular}

Berdasarkan data pada tabel 8 dapat dijelaskan bahwa responden berasal dari tingkat SD sebanyak 21 responden dengan persentase $81 \%$, diikuti dengan SLTP sebanyak 3 responden dengan persentase $11 \%$ dan SLTA sebanyak 2 responden dengan persentase $8 \%$.

d. Pengalaman Kerja

Data karakteristik responden berdasarkan pengalaman kerja dapat dilihat pada tabel 9.

Tabel 9. Distribusi jawaban responden berdasarkan pengalaman kerja

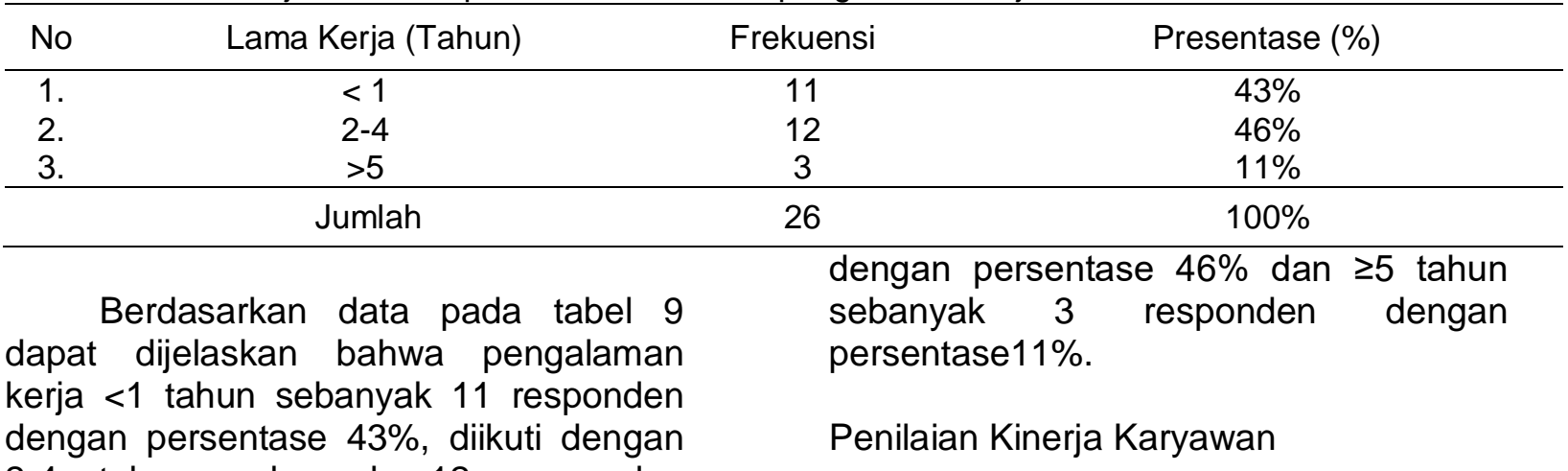


Dalam penelitian ini penilaian faktor kinerja karyawan diukur dengan 15 parameter yang meliputi kuantitas, kualitas, ketepatan waktu dan kehadiran yang didapatkan melalui kuesioner kepada para mandor pemanennya.
Setelah data diolah maka diperoleh hasil penilaian untuk masing-masing parameter dan nilai rata-rata untuk mengetahui kualitas parameter. Secara rinci tentang hasil penilaian kinerja karyawan dapat dilihat pada tabel 10

Tabel 10. Penilaian Kinerja Karyawan

\begin{tabular}{|c|c|c|c|c|c|c|c|}
\hline \multirow{2}{*}{ No } & \multirow{2}{*}{ Uraian } & \multicolumn{4}{|c|}{ Kriteria } & \multirow{2}{*}{ Nilai } & \multirow{2}{*}{ Kualitas } \\
\hline & & A & $\mathrm{B}$ & $\mathrm{C}$ & $\mathrm{D}$ & & \\
\hline 1. & $\begin{array}{l}\text { Karyawan mampu mencapai target yang } \\
\text { ditetapkan perusahaan }\end{array}$ & $\sqrt{ }$ & & & & 5 & Sangat Baik \\
\hline 2. & $\begin{array}{l}\text { Karyawan mampu melebihi target } \\
\text { perusahaan }\end{array}$ & $\sqrt{ }$ & & & & 4.81 & $\begin{array}{l}\text { Sangat } \\
\text { Baik }\end{array}$ \\
\hline 3. & $\begin{array}{l}\text { Karyawan anda rata-rata target yang dicapai } \\
\text { diatas target }\end{array}$ & $\sqrt{ }$ & & & & 4.38 & Sangat Baik \\
\hline 4. & $\begin{array}{l}\text { Karyawan berusaha bekerja lebih baik dari } \\
\text { karyawan lainnya }\end{array}$ & $\sqrt{ }$ & & & & 4.73 & Sangat Baik \\
\hline 5. & Tandan buah segar (TBS) disusun rapi & & $\sqrt{ }$ & & & 5 & Sangat Baik \\
\hline 6. & $\begin{array}{l}\text { Berondolan dipungut dengan baik dan } \\
\text { ditempatkan di tempat pengumpulan hasil } \\
\text { (TPH) }\end{array}$ & & $\sqrt{ }$ & & & 4.84 & $\begin{array}{l}\text { Sangat } \\
\text { Baik }\end{array}$ \\
\hline 7. & $\begin{array}{l}\text { Karyawan memanen buah yang sesuai } \\
\text { kriteria matang panen }\end{array}$ & & $\sqrt{ }$ & & & 4.88 & $\begin{array}{l}\text { Sangat } \\
\text { Baik }\end{array}$ \\
\hline 8. & $\begin{array}{l}\text { Karyawan menyelesaikan pekerjaan dengan } \\
\text { baik dan teliti }\end{array}$ & & $\sqrt{ }$ & & & 4.77 & $\begin{array}{l}\text { Sangat } \\
\text { Baik }\end{array}$ \\
\hline 9. & $\begin{array}{l}\text { Karyawan anda menyelesaikan pekerjaan } \\
\text { tepat waktu }\end{array}$ & & & $\sqrt{ }$ & & 5 & Sangat Baik \\
\hline 10. & Karyawan disiplin waktu dalam bekerja & & & $\sqrt{ }$ & & 4.84 & $\begin{array}{l}\text { Sangat } \\
\text { Baik }\end{array}$ \\
\hline 11. & Karyawan tidak menunda pekerjaan & & & $\sqrt{ }$ & & 4.73 & $\begin{array}{l}\text { Sangat } \\
\text { Baik }\end{array}$ \\
\hline 12. & $\begin{array}{l}\text { Karyawan mampu menyelesaikan pekerjaan } \\
\text { dengan cepat sebelum batas waktu yang } \\
\text { ditentukan }\end{array}$ & & & $\sqrt{ }$ & & 4.92 & Sangat Baik \\
\hline 13. & $\begin{array}{l}\text { Karyawan memiliki tingkat kehadiran yang } \\
\text { tinggi }\end{array}$ & & & & $\sqrt{ }$ & 5 & Sangat Baik \\
\hline 14. & $\begin{array}{l}\text { Karyawan datang bekerja sesuai waktu jam } \\
\text { kerja yang telah ditentukan perusahaan }\end{array}$ & & & & $\sqrt{ }$ & 4.27 & Sangat Baik \\
\hline 15. & Karyawan juga bekerja dihari libur & & & & $\sqrt{ }$ & 4.23 & $\begin{array}{l}\text { Sangat } \\
\text { Baik }\end{array}$ \\
\hline & Jumlah & & & & & 71.4 & \\
\hline & Rata-rata & & & & & 4.76 & Sangat Baik \\
\hline
\end{tabular}


Berdasarkan data yang disajikan pada tabel 10 dapat dijelaskan bahwa dari 15 parameter kinerja karyawan yang diukur keseluruhannya bernilai sangat baik $(4,76)$.Pada kriteria yang masuk ke dalam kelompok kuantitas kinerja karyawan dapat disimpulkan mendapatkan nilai sangat baik, hal ini terkait dengan tercapainya target panen tandan buah segar (TBS) yang dihasilkan sesuai dengan ketentuan perusahaan, kualitas kinerja karyawan dapat disimpulkan mendapat nilai sangat baik, hal ini terkait dengan terselesainya tugas sesuai dengan standar yang ditetapkan perusahaan.Ketepatan waktu kinerja karyawan dapat disimpulkan mendapat nilai sangat baik, hal ini terkait dengan kesesuaian waktu penyelesaian kerja para pemanen sesuai dengan target perusahaan. Kehadiran dapat disimpulkan mendapat nilai sangat baik, hal ini terkait dengan keberadaan pekerja panen pada waktu jam kerja.

1. Premi Panen

Berdasarkan dari analisa yang dilakukan premi panen yang diberikan kepada karyawan sebagai upah kinerja karyawan yang diterapkan PT. Sentosa Kalimantan Jaya (SKJ) sudah baik. Karyawan panen Afdeling 4 dan Afdeling 5 sama-sama telah memenuhi basis panen dan lebih panen namum berbeda dari sisi premi dan capaian lebih janjang yang didapatkan Afdeling 4 lebih tinggi (255 janjang/orang) dibandingkan Afdeling 5 (245 janjang/orang). Hanya saja dari kedua Afdeling masih memiliki kendala yang berbeda, Afdeling 4 lebih memiliki kondisi lahan yang datar sedangkan Afdeling 5 memiliki kondisi lahan yang miring sulit dijangkau serta terdapat terasan. Sehingga kondisi lahan tersebut menyebabkan karyawan panen lebih lambat dalam hal melakukan kegiatan pemanenan.

Menurut Nugroho (2007) upah memainkan peran yang penting dalam produktivitas kerja karyawan, karena upah merupakan harga jasa-jasa yang telah diberikan karyawan untuk perusahaan sehingga karyawan merasa pekerjaan mereka dihargai oleh perusahaan dan upah akan memacu pekerjaan mereka. Semakin baik mereka bekerja maka semakin banyak pula upah yang mereka dapatkan. Hal ini sesuai dengan pendapat Simamora dkk., (2016) yang menyatakan bahwa peningkatan jumlah gaji dan insentif yang diberikan oleh perusahaan dapat meningkatkan produktivitas tenaga kerja pemanen dalam memanen tandan buah segar (TBS).

2. Karakteristik Responden

Berdasakan dari data hasil observasi di lokasi penelitian dapat diketahui bahwa frekuensi usia karyawan yang terbanyak adalah usia 20-30 tahun dengan persentase $39 \%$. Hal ini menunjukkan bahwa karyawan masuk pada usia yang produktif dalam melakukan kegiatan panen, sehingga diharapkan akan mampu menghasilkan produktivitas yang tinggi untuk perusahaan.

Hal tersebut sesuai dengan pendapat Simamora dkk., (2016) yang menyatakan bahwa pekerjaan untuk memanen tandan buah segar (TBS) tergolong ke dalam pekerjaan yang berat dan memerlukan fisik yang baik, sehingga banyak diisi oleh kelompok usia yang tergolong usia produktif muda.Jenis kelamin secara keseluruhannya adalah karyawan laki-laki sebanyak 26 responden dengan persentase $100 \%$. Hal ini diduga dalam pelaksanaan tugas dan fungsi pemanenan membutuhkan tenaga panen yang kuat untuk menghasilkan produktivitas tinggi mempengaruhi terhadap pendapatan karyawan panen. Menurut Sapariah (2015) bahwa jenis kelamin merupakan salah satu faktor yang dapat mempengaruhi kemampuan kerja dan juga menentukan dalam klasifikasi pembagian kerja. Pada umumnya laki-laki memiliki kemampuan lebih besar dibandingkan perempuan. Umumnya perempuan bekerja di luar mencari nafkah seperti mengurus rumah dan anak.

Adapun tingkat pendidikan karyawan panen, diketahui tingkat persentase paling tinggi berada pada kategori SD sebanyak $81 \%$. Hal ini diduga karena saat pemanenan di kebun lebih mengutamakan hasil kerja karyawan secara teknis yang tidak terlalu 
membutuhkan kemampuan secara teoritis, sehingga untuk jenis pekerjaan yang ada di pemanenan perusahaan lebih memberikan lowongan terhadap karyawan yang memiliki pengalaman tanpa melihat latar belakang pendidikannya.

Hal ini didukung oleh pendapat Simamora dkk., (2016) yang mengemukakan bahwa tenaga kerja pemanen di perusahaan sebagian besar memiliki pendidikan rendah, karena perusahaan tidak menetapkan standar pendidikan minimum yang tinggi dalam penerimaan tenaga kerja khusus lapangan. Hasil observasi pengalaman kerja di lokasi penelitian diketahui bahwa tingkat persentase paling banyak 2-4 tahun sebanyak $46 \%$, yang berarti bahwa karyawan panen tersebut telah memiliki pengalaman untuk bekerja sehingga terampil dan mampu dalam melakukan pekerjaan memanen tandan buah segar (TBS).

Menurut

Handoko (2014)

pengalaman kerja merupakan

penguasaan pengetahuan dan

keterampilan yang dimiliki karyawan.

Pengalaman tersebut hanya bisa didapatkan melalui tempat kerja. Dari persentase kedua $43 \%$ pengalaman kerja $<1$ tahun diduga pengalaman kerja pada karyawan panen tidak memerlukan pengalaman kerja yang lama, karena setiap karyawan panen sebelum melakukan kegiatan pemanenan ada apel pagi atau breafing yang memberikan arahan kepada pemanen.

\section{Penilaian Kinerja Karyawan}

Berdasarkan dari analisa data kinerja karyawan panen, diketahui bahwa kinerja karyawan yang meliputi kuantitas, kualitas, ketepatan waktu dan kehadiran sudah sangat baik $(4,76)$. Kinerja karyawan panen yang baik bukan hanya untuk mendapatkan hasil yang baik, kualitas prestasi kerja juga sangat diperhatikan. Namun dengan kondisi lahan yang sulit dijangkau pada saat pemanen tandan buah segar (TBS) terutama pada Afdeling 5 sehingga menyebabkan premi panen dan prestasi janjang antara kedua Afdeling terdapat perbedaan.Faktor yang mendorong tercapainya kinerja karyawan panen meskipun tingkat pendidikan rendah yaitu alat kerja yang memadai, upah yang memadai, dan fasilitas yang memadai. Menurut Bangun (2012) penilaian kinerja adalah proses yang dilakukan organisasi untuk mengevaluasi atau menilai keberhasilan karyawan dalam melaksanakan tugasnya. Penilaian dapat dilakukan dengan membandingkan hasil kerja yang dicapai karyawan dengan standar pekerjaan.

\section{KESIMPULAN}

1. Sistem premi panen yang diterapkan oleh PT. Sentosa Kalimantan Jaya (SKJ) sudah baik dan telah menjadi motivasi kepada pemanen untuk bekerja secara produktif dengan hasil yang mampu melebihi basis atau target panen yang ditetapkan oleh perusahaan. Rata-rata pemanen mampu memanen 255 janjang/orang janjang sedangkan basisnya adalah 135 janjang untuk Afdeling 4 dan rata-rata pemanen mampu memanen 245 janjang/orang janjang sedangkan basisnya adalah 135 janjang untuk Afdeling 5 perbedaan tersebut diduga karena adanya perbedaan kemampuan masing-masing pekerja, perbedaan kondisi lahan dan tanaman yang dipanen.

2. Karakteristik responden yang berkaitan dengan parameter kinerja karyawan panen, dari faktor usia yang didominasi adalah usia produktif 20-40 tahun dalam hal bekerja, jenis kelamin karyawan panen secara keseluruhan laki-laki sebanyak 26 responden, tingkat pendidikan karyawan panen mayoritas berpendidikan SD (sekoah dasar), sebagian besar karyawan yang ada juga sudah cukup memiliki pengalaman 2-4 tahun hal tersebut menjadi faktor yang cukup mendukung bagi keberhasilan kerja karyawan panen.

3. Kinerja karyawan panen PT. Sentosa Kalimantan Jaya (SKJ) telah terlaksana dengan sangat baik $(4,76)$ 
hasil dari kuantitas, kualitas, ketepatan waktu dan kehadirannya. Hanya saja dari perbedaan kondisi lahan pada kedua Afdeling sehingga hasil yang didapatkan berupa premi dan prestasi janjang juga berbeda. Perbedaan kondisi lahan dan kondisi tanaman seperti perbedaan umur tanaman yang dikaitkan dengan target kerja karyawan merupakan faktor yang harus diperhatikan oleh pihak perusahaan sehingga hasil panen karyawan akan lebih baik lagi.

\section{DAFTAR PUSTAKA}

Ghani. M. A. (2003). Sumber Daya manusia Perkebunan dalam Perspektif. Jakarta: Ghalia Indonesia.

Nugroho, A. (2007). Faktor-faktor yang mempengaruhi produktivitas kerja karyawan PT. Sari Husada Tbk. Unit II.

Ghani. M. A. (2003). Sumber Daya manusia Perkebunan dalam Perspektif. Jakarta: Ghalia Indonesia.

Nugroho, A. (2007). Faktor-faktor yang mempengaruhi produktivitas kerja karyawan PT. Sari Husada Tbk. Unit II.
Ariep, I. d. (2003). Manajemen Motivasi. Jakarta : Grasindo.

Bangun, W. (2012). Manajemen Sumber Daya Manusia. Jakarta: Erlangga.

Handoko. T, H. (2014). Manajemen Personalia dan sumber daya manusia. Yogyakarta: BPFE.

Kurniawati. F, M. D. (2018). Kajian Sosial Ekonomi Masyarakat sekitar perkebunan kelapa sawit PTPN III di Kab. Labuan Batu, Kec. Bilah Hulu Sumatra Utara.

Pardamean, M. (2011). Sukses membuka kebun dan pabrik kelapa sawit. Jakarta: Penebar Swadaya.

Mangkungara. A. P. (2009). Evaluasi Kinerja Sumber Daya Manusia. Bandung: Refika Aditama.

Sari. R. P. (2008). Pengaruh karakteristik individu dan lingkungan kerja karyawan pada CV. Kawan Kita Klaten.

Purwanto. (2016). Tips Sukses usaha dan berkebun kelapa sawit. Depok: Palapa.

Simamora. A. W. F, S. W. (2016). produktivitas tenaga kerja pemanen di PT. Perkebunan Nusantara VII Unit Kebun Kelapa Sawit Rejosari. 